\title{
Ethics and morality, principles and practice
}

\section{J. B. Stokhof}

Published online: 12 November 2018

(C) The Author(s) 2018

\begin{abstract}
The paper addresses the tension in Wittgenstein's work between an absolute and a more contextual approach to values. It argues that both are relevant, but that from a systematic point of view the contextual perspective has priority. The consequent commitment to a form of moral realism is discussed, and an analogy with normativity in the domain of language is adduced to provide further support.
\end{abstract}

Keywords Wittgenstein · Ethics · Morality · Value

\section{Introduction}

The remarks and observations pertaining to ethics and morality that are scattered across Wittgenstein's oeuvre display a tension between absoluteness and an apparent relativism. Ethics is often described as dealing with the absolute good; at other points Wittgenstein discusses moral questions in contextual terms. A similar and apparently concomitant tension can be observed between the individual and the social. This prompts, first of all, an exegetical question: Is the tension real, and was Wittgenstein really of two minds here? Or is the tension only apparent, and is there a way of interpreting his various remarks that makes them compatible? The exegetical issue is echoed by a systematic concern: Ethics seems to need absoluteness in order to escape from a relativism that would make it superfluous. But sensitivity to context is an important feature of the way in which we judge each other and ourselves. Is there a way in which these two can be balanced?

M. J. B. Stokhof $(\square)$

ILLC/Department of Philosophy, University of Amsterdam, Amsterdam, The Netherlands

E-Mail: M.J.B.Stokhof@uva.nl

Department of Philosophy, Tsinghua University, Beijing, China 
Closely related is a "phenotypical" consideration, which is that humans are not born as fully developed ethical and moral entities, but typically need to be educated to become one. Human infants get their training from the community they happen to be born in. The amount and form of training may vary: simple behavioral training by means of punishment and reward, learning by being exposed to the lives and deeds of exemplary figures, explicit instruction into a set of accepted rules. And the relevant size of the community may also be different: family, tribe, state, church. From this perspective, absolutism and contextualism appear in a different light. On the one hand, there is diversity of methods and results; on the other hand, there is a shared ability to be susceptible to moral education, whatever form it takes. ${ }^{1}$ The aim of the current article is to clarify the relationship between these two features: absoluteness and context, from an exegetical but also a systematic point of view.

A note on terminology before we proceed. In what follows, we will use "ethics" to refer to the kind of normativity that is absolute, i.e., that is typically formulated in terms of general principles and absolute values, and "morality" to indicate the kind of normativity that starts from concrete actions and decisions and that takes contextual considerations into account. The terminology is not standard, but then again, it is only terminology.

\section{Wittgenstein on ethics and morality}

Often when Wittgenstein talks about value, it is characterized in absolute terms. It applies across the board, it is unconditional, and it functions for everyone in the same way. Here are two examples from his early writings: ${ }^{2}$

If there is any value that does have value, it must lie outside the whole sphere of what happens and is the case. For all that happens and is the case is accidental. What makes it non-accidental cannot lie within the world, since if it did it would itself be accidental. It must lie outside the world. (Wittgenstein 1960, Tractatus 6.41)

Ethics so far as it springs from the desire to say something about the ultimate meaning of life, the absolute good, the absolute valuable, can be no science. What it says does not add to our knowledge in any sense. But it is a document of a tendency in the human mind which I personally cannot help respecting deeply and I would not for my life ridicule it. (Wittgenstein 1969a, “A Lecture on Ethics”)

\footnotetext{
1 On Wittgenstein and moral education, cf., McLaughlin (1995), Burbules and Smeyers (2002), Giarelli (2002); indirectly related is Cuypers (1995).

Also related is the question whether, and if so, how and to what extent, we are able to "transcend" our ethical and moral framework and access and appreciate that of others. This is a question that is discussed by Bastian Reichardt (2018) in the context of assessing Wittgenstein's relevance to political philosophy.

2 Many more examples can be provided and the observation as such is widely shared in the literature, cf., e. g., the early work of McGuinness (1966) and more recent work of Stokhof (2002), Plant (2004), Arnswald (2009; and other contributions to that volume by Dieter Mersch, Liam Huighes, Anja Wieberg, Jens Kertscher), and many others. Wittgenstein's "A Lecture on Ethics" (Wittgenstein 1969a) is a particularly rich source of material.
} 
But in his later work, too, we find Wittgenstein speaking of religious belief, which we take to be closely related to ethics, in a similar manner:

[...] he has what you might call an unshakeable belief; It will show, not by reasoning or by appeal to ordinary grounds for belief, but rather by regulating for all in his life. (Wittgenstein 1978, “Lectures on Religious Belief, I")

However, Wittgenstein also had a keen eye for the importance of context when it comes to determining the right course of action. The evidence here is more indirect and is mainly provided by what we know from conversations Wittgenstein had on these issues with friends and students. Here is an example that comes from recollections of Rush Rhees of conversations he had with Wittgenstein in 1942:

When I [i.e., Rhees] suggested the question whether Brutus' stabbing Caesar was a noble action (as Plutarch thought) or a particularly evil one (as Dante thought), Wittgenstein said this was not even something you could discuss. "You would not know for your life what went on in his mind before he decided to kill Caesar. What would he have had to feel in order that you should say that killing his friend was noble?" (Rhees 1965)

Note that normally Wittgenstein would dismiss considerations about, e.g., intention as not ethically relevant (This is actually one of the points that Rhees wants to make in his paper.). However, here he does acknowledge their importance for the moral judgement in question. Interestingly, as the next quote shows, this does not mean that Wittgenstein discards the conception of ethics as absolute:

If he has, say, the Christian ethics, then he may say it is absolutely clear: he has got to stick to her come what may. And then his problem is different. It is: how to make the best of this situation, what he should do in order to be a decent husband in these greatly altered circumstances, and so forth. The question "Should I leave her or not?" is not a problem here. (ibid.)

This seems to view Christian ethics as absolute in the sense that the details of the situation do not matter: The demand to stick with one's spouse applies, irrespective of the circumstances. But note that there still remains a moral problem: "What does it mean to be a decent husband?" And here the context is explicitly mentioned: "in these greatly altered circumstances." Apparently, the absoluteness of the ethical system does not preclude considerations concerning contextually shaped moral problems that do not have obvious and absolute solutions. ${ }^{3}$ So the task is to find a coherent account in which both absolute ethics and contextual morality can play a role.

\footnotetext{
3 In the secondary literature this aspect is less prominent, but cf., e.g., Biletzki (2009) for an analysis of the later Wittgenstein's views on religion that is similar in spirit.
} 


\section{Wittgenstein on the priority of ethics}

In our search for an account that gives both ethics and morality their proper due, it would seem ethics has the upper hand, in Wittgenstein's views. Morality typically is concerned with others, but ethics, Wittgenstein claims, is not:

Can there be any ethics if there is no living being but myself? If ethics is supposed to be something fundamental, there can. If I am right, then it is not sufficient for the ethical judgment that a world is given. Then the world in itself is neither good nor evil. For it must be all one, as far as concerns the existence of ethics, whether there is living matter in the world or not. And it is clear that a world in which there is only dead matter is in itself neither good nor evil, so even the world of living things can in itself be neither good nor evil. Good and evil only enter through the subject. And the subject is not part of the world, but a boundary of the world. (Wittgenstein 1979, Notebooks, 02/08/1916)

This seems to suggest that others-family, community-have no role to play, that ethics is concerned only with the isolated individual. But even this isolated individual, as a contingent human subject, drops out of consideration. For the absoluteness of ethics can have nothing to do with anything contingent, anything worldly, be this physical or human. The concept of the subject that Wittgenstein refers to is that of the transcendental subject, not an ordinary contingent human subject. Hence, the insistence on absoluteness seems to rule out any moral concerns from the sphere of the ethical.

Other passages, such as the following quote from the conversations Wittgenstein had with Waismann, seem to lend this further support:

Schlick says that there are two conceptions of the essence of the good in theological ethics: according to the more superficial view, the good is good because God wills it; according to the more profound view, God wills the good because it is good. I believe that the first conception is the more profound: good is what God commands. (Waismann 1979)

The ineffability of God then extends to the good: There is nothing further to say than the good is absolute and cannot be identified with any contingent feature of the world.

All this suggests strongly that for Wittgenstein ethics has conceptual priority, and that in his view ethics and morality are related accordingly. Ethics is absolute, morality is context-dependent. The relation between them is instrumental: It is by being moral that we realize the ethical ideal. And that relation is asymmetric: Morality is the result of application of ethics in context and moral judgments depend on ethical judgements. ${ }^{4}$

The main point that we need to investigate is the asymmetry and the specific directionality of the ethics-morality relation: Does this lead to a coherent picture? But before we enter into that discussion, let us first point out some of the things this view seems to take care of.

\footnotetext{
${ }^{4}$ For a more detailed account of this interpretation, cf., Stokhof (2002, Chap. 4).
} 
First of all, there is the absence of rational justification. For Wittgenstein this is a "design characteristic": Ethics needs to be ineffable, and hence lack the kind of rational justification that applies to an empirical theory. It is essentially via contingency considerations that the absoluteness that is attributed to ethics takes care of this. $^{5}$

And there is the idea of the constitutive nature of ethics. Our attitude toward someone who does not adhere to ethical principles, being as absolute as Wittgenstein takes them to be, is not to judge him/her as "insane," "eccentric," or as "engaged in a different game."' For any of these three judgments would exculpate such a person. But, in fact, we do, at least in principle, hold people responsible for breaking the rules, and we only accept an insanity plea, or an appeal to moral relativism, in a limited set of well-defined circumstances (and, "But I am eccentric" will never fly ...).

However, there are also a number of questions that absoluteness raises. One question concerns the constitutive nature of ethics. If I question a moral rule that prevails in a community, am I then ipso facto no longer part of that community? Could a community be characterized not just by its rules, but also by its practices for questioning those rules? ${ }^{7}$

The main issue concerns the internal stability of the position, in particular in view of the asymmetry between ethics and morality. The question is how we maintain absoluteness of ethics and account for morality's dependence on context without ending up in skepticism or dogmatism. Someone might feel that he needs to follow a rule in an absolute way while acknowledging that this may not apply to everyone. Then the rule functions as an absolute without being taken as an absolute. That means that the justification of how the rule applies to oneself needs to be independent of how one thinks it applies to others. There is no logical tension here, but there is definitely a psychological one. ${ }^{8}$

And then there is the problem of the relevance of others. The kind of absolutism that we see exemplified in Wittgenstein's views (and in many others) focusses on a self-centered, one-sided form of "unconditional commitment," in which there is no systematic role for considerations regarding others. That seems to fly in the

\footnotetext{
${ }^{5}$ Note that it does not rule out the kind of justification we would normally associate with mathematics; given Wittgenstein's specific views on logic and mathematics, that is also excluded (but for different reasons).

${ }^{6}$ As would be the case, if we would regard ethical principles as a kind of certainty, as suggested by, e.g., Kober $(1997,2007)$ and Pleasants (2008), and accept that by doing so we lack any grounds for arguing with or criticizing those who hold themselves to different moral standards than we do.

7 Think of the legal system and the way in which rules of that system can be questioned, changed, or upheld: A community is characterized also by the procedures it has for this.

${ }^{8}$ One may speculate that this psychological difficulty is one of the sources of religious and political intolerance. Note that relativists face an analogous problem. Someone might acknowledge a certain relativism in how a moral rule functions because he or she thinks that the demand the rule makes might differ with circumstances (who is subject to the demand, time, place, and so on). Psychologically this is the road from acknowledging a role for circumstance to the kind of skepticism that discards normativity and replaces it by habit and custom.
} 
face of what real problems look like. ${ }^{9}$ And it ignores the problem of the source of ethics and the role of moral education. We need an account of how ethics arise (and evolve) both at the phylogenetic as well as the ontogenetic level. In the moral sphere, education and evolution depend on one another, the sources from which they spring, viz., community and human nature, are co-dependent.

In Wittgenstein's writings there are indications suggesting that this was a concern for him as well. Compare, the following passages from Notebooks:

[Psycho-physical] parallelism, then, really exists between my spirit, i.e. spirit, and the world. Only remember that the spirit of the snake, of the lion, is your spirit. For it is only from yourself that you are acquainted with spirit at all. [...] Is this the solution of the puzzle why men have always believed that there was one spirit common to the whole world? And in that case, it would, of course, also be common to lifeless things too. (Wittgenstein 1979, Notebooks, 15/10/1916) And in this sense, I can also speak of a will that is common to the whole world. But this will is in a higher sense my will. As my idea is the world, in the same way my will is the world-will. (Wittgenstein 1979, Notebooks, 17/10/1916)

Through the transcendental subject, the self and the other are intrinsically related. Of course, that is still far removed from an account of the actual role of actual others. However, it is important to note that although all this sounds very Schopenhauerian (and, indirectly, Kantian) there is a crucial difference between Wittgenstein's and Schopenhauer's conception of the subject. The latter's approach is epistemological and ontological, but Wittgenstein's approach is logical and conceptual. The transcendentality of the ethical subject in Wittgenstein's analysis is with respect to the world as it appears to the discursive subject, not "the world as such." There are two notions of world in the Tractatus, one discursive, one ethical, and they represent two ways of dealing with one and the same reality. The world of the discursive subject is the world as "everything that is the case" (Tractatus 1; atomistic), that of the ethical subject is the world as "a (limited) whole" (Tractatus 6.45; holistic). From that perspective, the separated-ness and the unity of subjects, of self and others, are not necessarily in opposition. ${ }^{10}$ Be that as it may, in the moral sphere we have to deal with others, and it appears that in these passages Wittgenstein acknowledges this.

So, we find ourselves in the following situation. Ethics is absolute and focused on the self, whereas morality is contextual and involves both the self and the other. In both there is something we need to steer clear from. When we disregard the contextuality of morality, we may end up with a dogmatic form of ethics, which dismisses every individual or contextual consideration as irrelevant. But if we focus only on the contextuality of morality we run the risk of value skepticism, for then it is unclear how a context-transcendent ethics can be justified, or even constructed.

What is key is how we view the relationship between ethics and morality. If one is taken as conceptually prior to the other, we run the risk of not taking the other seriously enough. In what follows we will indicate two views on the relation

\footnotetext{
9 Ask Isaac how he felt about his father.

10 For a more detailed analysis, cf., Stokhof (2002, Chap. 4).
} 
between ethics and morality and briefly discuss their pros and cons. We will argue that the nonstandard view is to be preferred for systematic reasons but also that some support for it can be derived from other parts of Wittgenstein's oeuvre.

\section{Ethics and morality: principles first}

The standard view can be formulated in the following slogan, "Ethics engenders morality." In this view, ethics is applied via ratiocination about what it requires in combination with what the situation is like. ${ }^{11}$

A moral question is usually something of the form: "What am $I$ to do in this situation?" An ethical principle can be of a strictly general form: "One should do love one's neighbor," or it can be a general statement that contains parameterized arguments: "One should love one's neighbor in situations of type $Y$." In either case the ethical principle is not about me, and not about the particulars of the situation I am in.

But the moral problem is, so what is needed is instantiation and particularization so as to fit the principle to the situation in question. That is typically conceived as a rational, discursive process: Context determines instantiations of general terms and supplies relevant values for parameters. That is done via observation ("What is the situation like?") and ratiocination ("What principle is valid here? And what does its instantiation look like?"). The outcome is a strict derivation of the decision that the rule requires in the situation at hand.

The standard view thus nicely fits a generally accepted view on decision-making and action. Its appeal is obvious: With its emphasis on general principles and strict rules for applying them in concrete situations, it holds the promise of objectivity, of rationality, of universality. But there are problems.

First of all, people do not always act rationally and justify their actions rationally, they often act intuitively and spontaneously. But when they act that way we would still want to qualify their behavior normatively. However, if the standard view is right, in such cases there are no ethical considerations that have determined the action, which makes normative judgment problematic. Also, people can intentionally "go against the grain." After all, ethical principles are not compelling, we are dealing with normative not with causal necessity.

Secondly, people are not moral in and of themselves: Morality is a matter of being trained and educated, and much of that training is by means of "force" (socialization), example, and authority. The training may aim, implicitly or explicitly, at bringing about a state that satisfies the standard view, but what is crucial is that the steps that are needed to get there are as imbued with normativity as the envisaged end state.

Finally, ethics develops over time. It changes, for example, in the scope of application of ethical principles: think of transcending family and group limitations. And it also changes in terms of content, excluding behavior that was once ethically

11 This view is shared by a variety of ethical theories, which differ in many other respects. Interesting as these differences are, we can neglect them for the present purposes. 
permissible, or condoning actions that were considered unacceptable. The history of human thought about ethical issues clearly testifies to such changes. ${ }^{12}$

\section{Ethics and morality: practice first}

An alternative view starts from practice, rather than principles, and considers concrete moral decisions, actions, and judgments, made in context, as its base. It, too, can be formulated in a slogan: "Morality engenders ethics."

There are a number of reasons that one could adduce to support such an approach. First of all, we need to be educated, and, like any education, moral education starts in the midst of things: with concrete decisions, actions, and judgments, not with general rules. The link with actual practice is built right into the alternative view. Second, by giving practice such a central place, the connection between individual and other, between individual and community, is guaranteed. All practice involves community, education necessarily so. In this way the alternative view follows a typically Wittgensteinian move: if you want to know what something is (means ...), it is a good idea to look at how you have learnt it, how it is taught.

But the alternative view meets challenges of its own. A key issue concerns the bootstrapping problem: It needs to give an account of what must be assumed in order to make the process of morality-engendering ethics work, i.e., it needs to specify initial conditions that make morality possible. And it needs to face the challenge of avoiding skepticism: How we can transcend the situation-boundedness of morality and formulate ethics? If we cannot account for that, then it seems that relativism is unavoidable. And finally, there is individualism: We need an account that avoids the trap of locating everything in the individual, but we also need an account of how and why individuals can make choices that go beyond their moral education. ${ }^{13}$

In order to account for bootstrapping we need to make two significant assumptions: that there is such a thing as "moral induction" that serves as a basis for learning and generalization; and that there are such things as "moral facts" that moral induction operates on. These are controversial assumptions, and it is not at all obvious that they can be defended as such. ${ }^{14}$ But they do seem to be needed if one wants to make bootstrapping work. Let's take a closer look.

\footnotetext{
12 And we mark some of them as not just change but actual progress.

13 This is in many ways the same challenge as Reichardt (2018) identifies in his analysis of how Wittgenstein can be relevant for political philosophy: "Criticising forms of life" assumes the ability to transcends the boundaries of one's individual history and education; cf., also below.

14 Although moral realism has noteworthy defenders, such as G.E. Moore, McDowell, Parfit, Foot, and others, is not a mainstream view, especially not outside moral philosophy as such, at odds as it appears to be with prevalent forms of reductionism and materialism. Werhane (1992) discusses the relation between Wittgenstein and moral realism that takes on board early work by Lovibond and Blackburn; more recent is De Mesel (2015). For reasons of space, we have to leave a comparison between these analyses and the one presented here to another occasion.
} 


\section{Moral induction}

According to Wittgenstein's view on it that is outlined in On Certainty (Wittgenstein 1969 b), induction is not a law, or a reasoning principle, or a rule of inference, but a natural ability:

The squirrel does not infer by induction that it is going to need stores next winter as well. And no more do we need a law of induction to justify our actions or our predictions. (Wittgenstein 1969b, On Certainty, p. 287)

I might also put it like this: the "law of induction" can no more be grounded than certain particular propositions concerning the material of experience. (Wittgenstein 1969b, On Certainty, p. 499)

Induction is the ability that enables us to transcend a given situation with respect to features of situations that matter to us. Physical features such as the rhythm of day and night, the changing of the seasons, their effects on other animals and plant life, and hence on opportunities that await us and the threats that we face, are typically features of situations that we depend on for our survival and for which we have developed a natural ability to observe and recognize. ${ }^{15}$

There seems to be no principled reason why this ability, or set of abilities if one prefers, would be limited to just observable physical features of situations, and could not extend to include features that involve social and cultural traits. Moral induction would then be the ability to observe and act upon moral features of situations, and to do so across situations.

\section{Moral facts}

Moral induction assumes that morally relevant features do indeed exist, viz., that there are such things as moral facts. ${ }^{16}$ These would be features that are tied to human existence, and that evolve with it over time. Human existence cannot be reduced to human nature in a purely physiological sense, it is what is to be human, and as such intrinsically tied to how we humans conceive ourselves. ${ }^{17}$ That makes them not completely "man-made," yet also not completely "written in stone," i.e., biologically determined. So, moral facts are objective, yet not absolute in the sense of being completely context-independent.

\footnotetext{
15 Wittgenstein's view here has affinities with accounts of embodied cognition that center around the concept of "affordance" as explored in work by, among others, Chemero, Rietveld, Kiverstein, Bruineberg; cf., e.g., Rietveld and Kiverstein (2014). There the starting point is that animals (including humans) are attuned to specific action possibilities that their environment ("niche") provides, and this extends beyond physical features and extends to the social environment.

16 The use of "fact" might strike the wrong chord for some, what matters is that these features are objective (perhaps in a species-relevant way) and action-guiding and cannot be reduced to purely physical features of the environment.

17 This is one reason why imagination of what we are and, in particular, imagination of what we could be, as, for example, literature provides, is (also) of moral importance.
} 
Examples would be self-consciousness and the idea of personal duties and rights; acknowledgment of human-ness of others and the extension of the moral sphere so as to include them; the embodied nature of human existence and the right to bodily integrity and the duty to respect the integrity of others. In each case we have a natural fact that at the same time constitutes a morally relevant feature to which we are attuned, or that we can be made to be attuned to. Over time, these may change, e.g., when the conception of who is human to begin with changes, or when changes appear in what being human means in the sense of duties and rights. Thus, moral facts are closely connected with the notorious Wittgensteinian concept of "a form of life."

At this point there is a concrete link between the current discussion of ethics and morality and the analysis of Wittgenstein's relevance for political philosophy of Bastian Reichardt that was already referred to above. Reichardt formulates it thus:

In the light of Wittgenstein's later work, the task of political philosophy can be regarded as finding possibilities to resolve those contradictions between forms of life which impede our coexistence while, at the same time, accepting the fact that there is a fundamental difference between forms of life. (Reichardt 2018)

In order for this to be possible, Reichardt argues, the concept of a form of life has to be construed as having both individual and communal traits, and as being temporally and socioculturally contingent. This provides further support for the analysis proposed here.

Note that we still call these features moral facts, and not ethical facts. Although they are not strictly tied to one situation, they are situational in that they may change over time, may differ from one community to another, and so on.

Note also that it is the correspondence with natural facts (e.g., characteristic biological traits of humans) that allows us to track them across situations; this is part of why moral induction works.

This can be viewed as a kind of nonreductive naturalism: Moral facts are facts of nature, but of our nature, and their existence, and their content, is intrinsically tied to what we are. The right to bodily integrity is the ethical analogue of our bodily way of existence; the duty to secure this right for others, that of the insight that this is a form of life that we have in common.

This leaves much undecided. It certainly does not allow for a strict inference to all the rules and regulations that we actually have, since there is a lot of lee-way for accidental, i.e., historically and culturally set, parameters. Nor does it follow that ethical facts apply to humans only: One might well argue that ethics pertains to all "sentient beings," i.e., co-occurs with consciousness as such, not just human consciousness. Where there is a body and some form of self-awareness, there is the possibility of suffering, and along with that a body of moral facts pertaining to it. 


\section{Challenges}

Of course, the alternative view has its own challenges. One obvious concern is that to hold that morality engenders ethics might imply skepticism. The contextualism that is at stake reflects the human condition: Humans have to reason and decide which action to perform with only limited resources, i.e., partial knowledge of relevant circumstances, limited powers of reasoning. This makes the outcomes of actions unpredictable. And then there are, of course, genuine conflicts of interest.

However, it is the same "limitations of the human condition" that make context relevant, even unavoidable, in the first place. It also constrains "moral induction." Obviously, there is a good side to this: Awareness of these limitations counteracts dogmatism, and a bad side-it is a potential source of differences.

At this point the idea of absolute value, which is not the same as absolute value as a reality, enters. From the current perspective, absolute value cannot be conceived as a general rule, a maxim, or a universal principle. Rather, it has to be construed as a stance, as an attitude with which we try to confront the various contextually specific decision problems that we face. It embodies what we take various situations to have in common, and thus functions as a guideline, as a means to overcome the limitations of context.

This general stance affects how we deal with a contextually specific situation, but it does not determine how we should deal with it. In Wittgenstein's writings, the general stance is reflected in the "ethical experiences" that he refers to in "A lecture on ethics" (Wittgenstein 1969a). These experiences are not even in their formulation "rule-like," they instead describe with what kind of mindset we enter into the messy business of dealing with a moral issue.

From this perspective, the ethics that is engendered by morality has a regulative status. Although generally formulated principles might play a role, the driving force is rather a transformative attitude that aims at their realization without losing sight of the need to always take context into account.

Now the formulation of this ethical stance might also look self-centered, inasmuch as it appears only to guides one in one's actions as an individual. However, what it guides me in is decision-making and acting in concrete situations that (almost) always involve others. That is, the stance as such comes from the contexts, not the other way around, and there is no strictly individual-based account of morality that would support a self-centered ethical stance.

\section{Normativity in other domains: meaning}

To illustrate that the kind of questions and considerations that have been treated above are not limited to the case of ethics and morality, we take a very brief look at one other debate in which similar issues arise, viz., the debate around meaning normativity. 
The leading question in that debate is whether meaning has a normative dimension, i.e., whether conditions for correct use of linguistic expressions are part of their meaning, and if so, how to account for that. Most authors agree that there is normativity linked to meaning, but they disagree about the nature of the relationship. ${ }^{18}$

In the debate there is agreement on two features of meaning normativity that limit possible answers. The first is that it is action-guiding, it steers action in certain ways, but not action-determining, there is always a possibility of "going against." The second is that it allows for intersubjective normative judgments. ${ }^{19}$

These are global and fairly intuitive constraints on the explanation of most forms of normativity. The first one distinguishes normative from nomological-causal connections, and here accounts for the possibility of intentional deviations (metaphor, irony, etc.) and for fact that unintentional deviations (mistakes) do not automatically lead to incomprehensibility. The second constraint places normativity in the context of interactions: This means normativity is not an individual, but a social phenomenon, language users judge each other's utterances and, by and large, accept those judgments.

The issues are complex, also because in some approaches meaning normativity is intrinsically related to epistemological and cognitive issues, and various solutions have been proposed. What position one takes is not just a theoretical issue. Different views construct the relationship between semantics and pragmatics differently, so they have different consequences for linguistic theory and linguistic methodology, and potentially lead to different empirical predictions.

However, this is not the place to go into the details, nor do we need to: What is relevant here is that the debate has some interesting similarities to what we are concerned with in this article. One of these is that we can isolate two basic perspectives that are quite similar to the ones we have discussed above as the standard and the alternative view. The first is that meaning engenders normativity, i.e., that it is the meaning of expressions that is the source of the normative constraints on their use. The second constructs the relation the other way around: Normativity engenders meaning, i.e., meaning arises from normatively constrained use of language.

The so-called interaction model of Inès Crespo (2009), in which meaning normativity arises from the need to justify use in communicative situations objectively, i. e., to a hypothetical outside arbiter. This model regards linguistic interaction as the source of meaning normativity, and thus gives a central role to the community, to learning and training, and assumes some form of normative naturalism. It balances contextual considerations and context-transcendent ones. It does not construe actual use-in-context as somehow derived from, or constrained by, independently existing normative conditions. And it accounts for intersubjectivity and context-transcendence, and hence avoids meaning skepticism, by means of an appeal to fundamental

\footnotetext{
18 The debate originated in Kripke's essay on Wittgenstein's rule-following considerations (Kripke 1982) and then developed into a debate in semantics proper. Boghossian (1989) is often acknowledged as one of the primary sources; some key contributions are Hattiangadi (2006), Whiting (2007), Glüer and Wikforss (2010), Gibbard (2012), and Glüer and Wikforss (2015).

19 Note that similar features inform the discussion about ethics and morality.
} 
characteristics of language users, i.e., their natural ability to observe and be guided by normative aspects of their environment. ${ }^{20}$

As was already noted, the debate around meaning normativity originated in exegetical work on Wittgenstein's rule-following considerations. And these contain key elements that also play a role in the current discussion: the concept of normative naturalism; the role of training and education; the interdependence of individual and community.

This has consequences for the exegesis of Wittgenstein's work. The emphasis on the individual that seems to characterize his views of ethics has struck people as in odd opposition to the central role of the community when it comes to language and meaning: "ethical individualism" versus "language as a social art." If normativity in language and in ethics works in similar ways, that becomes less of an opposition, and more a matter of continuity, and thus makes for a more coherent overall view. ${ }^{21}$

\section{Conclusion}

We have identified two ways in which relationship between ethics and absolute value, and morality and contextual dependence can be construed. The view that "ethics engenders morality" has been found to be unstable and unsatisfactory as an explanatory factor. The alternative view, that "morality engenders ethics," is (more) stable. It is explanatory only given substantial assumptions but seems sufficiently grounded in Wittgenstein's remarks to be exegetically possible.

The core assumptions are definitely at odds with commonly accepted views. They oppose methodological individualism, standard rationality assumptions in action explanation, and reductive forms of naturalism. But similar phenomena in other domains, such as meaning normativity, can be argued to require similar moves against these views.

The resulting view has the advantage of putting Wittgenstein's view on ethics and morality more in line with other themes in his work, in particular the rulefollowing considerations, thus supporting a more coherent overall reading. It also seems promising from a systematic point of view, but that obviously needs further work.

Acknowledgments This material has been presented at the Wittgensteinian Approaches to Moral Philosophy conference at KU Leuven, and at Beijing Normal University. I would like to thank the audiences for their feedback. I owe a special thanks to Bastian Reichardt for his suggestion that we publish our papers back-to-back and for his insightful comments.

Open Access This article is distributed under the terms of the Creative Commons Attribution 4.0 International License (http://creativecommons.org/licenses/by/4.0/), which permits unrestricted use, distribution,

\footnotetext{
${ }^{20}$ It is worth noting that Crespo developed her approach to semantic normativity on the basis of a study of models of normativity in ethical theory.

21 By itself that is not a convincing argument, after all, why would a coherent interpretation be closer to the truth than an incoherent one? But it does remove the need for explanations that appeal to more than just the work itself, such as Louis Sass's analysis in terms of Wittgenstein's alleged "schizoid" personality (Sass 2001).
} 
and reproduction in any medium, provided you give appropriate credit to the original author(s) and the source, provide a link to the Creative Commons license, and indicate if changes were made.

\section{References}

Arnswald, Ulrich. 2009. The paradox of ethics-'It leaves everything as it is'. In In Search of Meaning. Ludwig Wittgenstein on Ethics, Mysticism and Religion. Ed. Ulrich Arnswald. Karlsruhe: Universitätsverlag Karlsruhe, 1-24.

Biletzki, Anat. 2009. De-transcendentalizing religion. In Wittgenstein's Enduring Arguments. Eds. Edoardo Zamuner and D. K. Levy. Oxford: Routledge, 245-261.

Boghossian, Paul. 1989. The rule-following considerations. Mind 98, 507-549.

Burbules, Nicholas \& Smeyers, Paul. 2002. Wittgenstein, the practice of ethics and moral education. Philosophy of Education, 248-257.

Crespo, Ines. 2009. Normativity and Interaction: From Ethics to Semantics. MSc thesis, ILLC, Amsterdam.

Cuypers, Stefaan. 1995. What Wittgenstein would have said about personal autonomy. Studies in Philosophy and Education 14, 251-265.

De Mesel, Benjamin. 2015. Wittgenstein and objectivity in ethics: A reply to Brandhorst. Philosophical Investigations 40, 40-61.

Giarelli, James. 2002. On Wittgenstein, the practice of ethics, and moral education. Philosophy of Education, 258-261.

Gibbard, Alan. 2012. Meaning and Normativity. Oxford: Oxford University Press.

Glüer, Kathrin \& Wikforss, Asa. 2010. The normativity of meaning and content. The Stanford Encyclopedia of Philosophy. Ed. Edward Zalta, Stanford: Stanford University.

Glüer, Kathrin \& Wikforss, Asa. 2015. Meaning normativism: Against the simple argument. Organon F22 Supplementary Issue, 63-73.

Hattiangadi, Anandi. 2006. Is meaning normative? Mind and Language 21, 220-240.

Kober, Michael. 1997. On epistemic and moral certainty: A Wittgensteinian approach. International Journal of Philosophical Studies 51, 365-381.

Kober, Michael. 2007. 'In the beginning was the deed': Wittgenstein on knowledge and religion. In Readings of Wittgenstein's On Certainty. Eds. Daniele Moyal-Sharrock and William H. Brenner. Basingstoke: Palgrave Macmillan, 225-250.

Kripke, Saul. 1982. Wittgenstein on Rules and Private Language. Oxford, Blackwell.

McGuinness, B. F. 1966. The mysticism of the Tractatus. The Philosophical Review 75, 305-328.

McLaughlin, Terence. 1995. Wittgenstein, education and religion. Studies in Philosophy and Education 4, 295-311.

Plant, Bob. 2004. The wretchedness of belief. Wittgenstein on guilt, religion, and recompense. Journal of Religious Ethics 32, 449-476.

Pleasants, Nigel. 2008. Wittgenstein, ethics and basic moral certainty. Inquiry 51, 241-267.

Reichardt, Bastian. 2018 Criticizing forms of life. Weighing Wittgenstein's role in political theory. Zeitschrift für Ethik und Moralphilosophie, 1.

Rhees, Rush. 1965. Some developments in Wittgenstein's view of ethics. The Philosophical Review 74, 17-26.

Rietveld, Erik \& Kiverstein, Julian. 2014. A rich landschape of affordances. Ecological Psychology 26, 325-352.

Sass, Louis. 2001. 'Deep disquietudes': reflections on Wittgenstein as anti-philosopher. In Wittgenstein. Biography and Philosophy. Ed James Klagge. Cambridge: Cambridge University Press, 98-155.

Stokhof, Martin. 2002. World and Life as One. Ethics and Ontology in Wittgenstein's Early Thought. Stanford; Stanford University Press.

Waismann, Friedrich (ed). 1979. Ludwig Wittgenstein and the Vienna Circle. Oxford: Blackwell.

Werhane, Patricia. 1992. Wittgenstein and moral realism. Journal of Value Inquiry 26, 381-393.

Whiting, Daniel. 2007. The normativity of meaning defended. Analysis 67, 133-140.

Wittgenstein, Ludwig. 1960. Tractatus Logico-Philosophicus. Frankfurt a/M: Suhrkamp.

Wittgenstein, Ludwig. (1969a) A lecture on ethics. Philosophical Review 74, 3-12.

Wittgenstein, Ludwig. (1969b) Über Gewißheit. On Certainty. Oxford: Blackwell.

Wittgenstein, Ludwig. 1978. Lectures on Religious Belief. In Lectures and Conversations on Aesthetics, Psychology and Religious Belief, Oxford: Blackwell.

Wittgenstein, Ludwig. 1979. Notebooks 1914-1916. Oxford: Blackwell. 